\title{
A Study on Affective Barriers in Intercultural Communication and Related Strategies
}

\author{
Sha Zhu \\ School of Foreign Languages, Huaiyin Institute of Technology, Huai'an, Jiangsu, China
}

\begin{abstract}
Intercultural communication acts a pivotal part in international activities and there are many barriers involved in it. If the communicators are short of the understanding of the barriers in the process of intercultural communication, especially the affective barriers, the whole interaction will be affected; even worse, there will be some serious conflicts. Thus, this paper will study the affective barriers in intercultural communication, analyze the possible causes of the barriers, and put forward some effective strategies to help communicators enhance their cross-cultural competence.
\end{abstract}

Index Terms - intercultural communication, affective barriers, strategies

\section{INTRODUCTION}

With the economic globalization advancing, more and more countries in the world are involved, which has particularly increased the need for effective international communication. There are some common barriers in the process of intercultural communication, like verbal barriers and nonverbal barriers. However, in reality, there still exists another more practical problem, even for those with some intercultural experience, that is, the affective barriers, which are deeply entrenched in people's attitudes and values.

According to Starosta (2007), the way human behave is dictated by the way they perceive the world, and a person's culture has a strong impact on the perception process, therefore, if someone is quite confused about the new culture and even refuses to get to know the new ways or habits in that culture, some misunderstandings based on the different perceptions probably happen between the communicators with diverse cultural backgrounds. Different from other barriers, affective barriers are caused by people's different perceptions about the same thing, including ethnocentrism, stereotyping, prejudice, racism and anxiety with uncertainty (Yan, 2009). Compared with other intercultural barriers, the affective barriers are deep rooted in thinking and more difficult to overcome, worthy of more research.

\section{AFFECTIVE BARRIERS IN INTERCULTURAL COMMUNICATION}

\section{A. Ethnocentrism}

Ethnocentrism is the belief that one's own cultural background, including ways of analyzing problems, values, beliefs, language, etc. is superior(Wang, 2008). Thus, people are habituated to believing that all the rules and experiences from their own culture are appropriate and correct. They take it for granted that their cultural behaviors and thoughts are the standard. Naturally, according to them, the different behaviors and ideas from other cultures are inappropriate and even wrong by instinct. The following is a case about it.

Ms. Liu, an excellent Chinese assistant, was sent to work in an American company. She worked very hard and followed the boss's orders with few personal ideas as she had always done in China. However, she was often asked questions by the boss about some issues of the work itself, and she felt quite confused. At the same time, the boss was not satisfied with her working attitude since she could not give expected suggestions. (Li, 2002)

In traditional Chinese culture, in some organizations, following orders without too many additional personal ideas is common for some work. Therefore, Ms. Liu felt uncomfortable when she was asked many questions about the job tasks. Her reactions reflected a typical ethnocentric attitude. When she was in a completely new culture, she didn't try to understand the new ways in that culture. The boss also shared the same attitude, which led to the misunderstanding between each other.

Another case is that a Chinese student Lin Ling went to America to attend a training. She found some teachers there dressed casually and often to sit on the desks when having classes. The teachers just gave lectures for a little time while asked the students to discuss and make reports more. Lin Ling was unaccustomed to such teaching method. Besides, her American classmates didn't seem to respect the teachers so much in that they called the teacher's name directly and argued with the teacher straightly in class. When she gave a speech, her classmates often asked her questions and argued with her, which always embarrassed her. So, she felt that American classmates were hostile to her. (Li, 2010)

Lin Ling could not adjust to the American teaching method and even had the wrong feeling of her classmates' hostility because in different cultures, there are different ways to teach and to show respect. Evidently, Lin Ling used her own cultural ways as the standard to measure and judge other culture, which formed her ethnocentric attitude towards the new culture. 
In fact, more cultural differences than cultural similarities exist among different countries, but people tend to use their own ways as the criterion, so they are not able to accept others' ways easily. Further, some of them even have little respect for the other cultures, let alone cooperate with people from other cultures. For example, in the COVID-19 pandemic, people have extremely contrasting understandings of wearing the facial masks. In China, wearing the masks is to protect oneself from the infection. However, in some cultures, it is widely accepted that only the sick people wear masks. Some conflicts may be caused by the different even contradicting understandings of the same issue.

\section{B. Stereotyping}

Stereotyping is another major affective barrier in intercultural communication. It is the overgeneralized and oversimplified beliefs people use to categorize a group of people (Starosta, 2007). It is the product of lazy and limited perceptions of some people, who are always prone to fit people into the fixed patterns according to their previous experience. Such people often base their behavior toward outgroup members on stereotype-related expectancies (Gudykunst, 2007). Stereotyping permits people to overlook the differences within people in a particular group, and they fail to take into the individual characteristics account.

There are mainly five dimensions of stereotypes: direction, intensity, specificity, consensus and accuracy (Starosta, 2007). The direction of stereotypes means the stereotype is either positive or negative, and the positive ones as "the Chinese are good at math" or the negative ones as "the Chinese cannot be a strong leader". The intensity of stereotypes means how rooted the stereotype is in the speaker's and receiver's minds. Some stereotypes are held strongly while others are held loosely. The specificity of a stereotype indicates whether it is vague or concrete. More concrete stereotype is easier to rebut than the vague one in that the general statement may have more than one understanding. The consensus of stereotypes relates to whether the stereotype is widespread within a community. Some stereotypes may come to mind easily even with a faint reference. The accuracy of a stereotype tells how accurate the stereotype describes about the certain group.

There are many categories of stereotypes, including race, country, region, religion, gender, age, occupation, social class, even physical characteristics. The following is a case.

Mr. Brown, the manager of a company, was talking with Mr. Black, the manager of another company, for the cooperation of an international project. They had a pleasant and smooth communication and intended to sign the agreement in ten days. Soon after, Mr. Brown discovered that Black was from Pakistan. Since he thought that Pakistanis were not trustworthy, he decided to cancel the cooperation. (Cao, 2019)

Apparently, Mr. Brown had a negative judgment about Pakistanis based on his previous perception. He overgeneralized and failed to specify Black's own characteristics, which was a typical stereotype, pitifully leading to the lost of a potential client.

People have grown up with their own cultural and educational backgrounds, and the perceptions in the childhood and later phases of life have left a preliminary impression on some of them to gradually form a fixed pattern. Once with the mindset, when meeting the stereotyped group in the process of communication, they tend to unconsciously look for these set features without thinking twice, which further deepens the previous stereotype. For instance, for some Chinese businessmen, they regard westerners are so serious and rigid that they won't make changes easily in negotiation. For some western businessmen, they think the Chinese regard friendship so importantly that they often ignore business rules. In the business field, stereotyping is also quite harmful.

\section{Prejudice and Racism}

When certain stereotypes against a group of people are consistent, there will be prejudice, which refers to the irrational dislike, suspicion, or hatred of a particular group, race, religion, or sexual orientation. According to Starosta(2007), there are five common forms of prejudice: verbal abuse, physical avoidance, discrimination, physical contact and massacre. Verbal abuse can be in the way of name labeling and even ethnic jokes. For example, in the following conversation: how do you know the Asians move in? When the Mexicans start getting car insurance. This impolite joke reflects two prejudices: one is that Asian people are bad drivers and the other indicates Mexicans are impoverished. What's more, when some people dislike the other group of people, physical avoidance often occurs with the form of isolation. Another one is discrimination, which can be the way of a refusal to give equal opportunities to the members in other groups in the fields of political rights, education, employment, entertainment, etc. Massacre, as the catastrophic way, is the genocidal slaughter, which is closely connected with racism, which is the policy, practice, belief, or attitude against individuals just based on their race. It is a very negative, unfair and biased attitude towards a certain group of people. This year, the whole world is haunted by the COVID-19 pandemic. The following is a relevant example.

A Singaporean student was walking on the street of London with the masks on his face, and suddenly he was attacked by four British people, who kicked and punched him, resulting in fracture. The boy said that he just couldn't understand why these people would be so impulse and unreasonable.

Obviously, in the case, the attackers hold prejudice against Asians with masks. In fact, wearing the masks has been a very accessible and effective way to protect oneself from the infection so far. However, these people just think from their own perspective, insist on their prejudice and further impose physical bullying on the boy, a reflection of their superiority, which is unfair and exasperating. 


\section{Anxiety and Uncertainty}

In the process of communication, people may feel nervous because they have no idea about what other people think and do not know how to cope with others. Thus, sometimes they focus so much on their own feelings that they forget to concentrate on the message itself. Besides, in the intercultural contact, people are likely to have more stress and anxiety since they are in a group to which they do not belong. When they are not sure what to say and what to do, they would hesitate to give expected responses, which will give rise to some misunderstandings in intercultural communication.

Here is a typical case. Sun Jun, from China, and Charles Thomson, from New Zealand, were discussing an international engineering project. It was the first time Sun Jun talked with a foreigner. When Charles put forward his ideas, Sun Jun felt a bit of nervous and anxious, so he just kept nodding his head and said "Um", "Yes" and "Uh huh". When Charles finished his statement and asked Sun's opinion, Sun replied: "I don't think that project will work." Feeling angry, Charles asked, "Then why did you pretend to agree with me all the time?" (Pang, 2010)

In the case, it is because he focused so much on his own negative feelings that Sun Jun failed to respond and behave appropriately. At last, Charles felt disrespectful and irritated.

\section{POSSIBLE REASONS OF AFFECTIVE BARRIERS}

Firstly, the lack of the intercultural awareness and related knowledge is one of the reasons of these affective barriers. Although human beings are physically similar, the responses to the same things are quite contrasting. Without the necessary intercultural awareness, people tend to overlook the crucial cultural differences. Moreover, without the related cultural knowledge, communicators with different backgrounds may be prone to misjudge others and some misunderstandings are inevitable.

Among so many cultural differences, understanding the difference in cultural values can help us deeply know and even appreciate a new culture. If we could understand how values vary among different countries, we are more likely to interpret the behaviors in a new culture. For example, individualism is the source of western culture, which holds that a person is supposed to think or judge independently and the individual can do whatever they want, so their freedom and rights are paramount. For these people from such cultures, they are taught to value themselves, even in building friendships with others. Therefore, English speakers are always assertive in communicating with others and can express their views and feelings quite directly. On the other hand, Eastern people think highly of collectivism, which emphasizes the views and the needs of the group more than the individual. In collective culture, people are taught to consider both the group interest and the individual interest, however, with the group benefit as the priority if the two contradict with each other. That's why the easterners are fairly modest and implicit in speaking.(Yu,2009) Thus, with different consideration in the value system, different cultures have its own ways to do things in daily life, such as ways of eating, dressing, making friends, and knowing what is right, what is wrong, what is useful and what to strive for and even what to die for, etc. For most time, the varying customs in different cultures are neither right nor wrong, therefore what we need to do is trying to respect the new culture first, and then learn and understand that culture we are not familiar with as much as possible.

Secondly, easily influenced by others can be another major reason for ethnocentrism, stereotyping, prejudice and racism. Some perceptions could be started in the children's early socialization, and gradually cultivated in their interactions with other people, especially when they are not able to think independently. For instance, children could be affected by their parents' behaviors, manners and words, such as: "we don't associate with people like that". When they have more contact with people in society, they may naturally put people into different groups, resulting in the deepening of some negative perceptions. When meeting some people from quite different cultural backgrounds and further having conflicts, some of them will not be open-minded and even be very violent.

Thirdly, some people like to label and categorize other cultures for the sake of superiority to gain psychological benefit, even economic benefit for themselves. They are prone to attribute problems to another group of people. With such negative thought, to solve the problem itself is becoming increasingly difficult and gradually the problem will be more and more severe to far be beyond them.

\section{STRATEGIES OF EFFECTIVE INTERCULTURAL COMMUNICATION}

In spite of the affective barriers discussed above intertwined in the intercultural communication, we can still have efficient and successful interaction with more efforts. Hence, in this part, several feasible strategies will be proposed to improve the intercultural communication ability.

\section{A. More Learning of Target Culture}

More understanding of the target culture can facilitate intercultural communication and overcome certain affective barriers. Mastering relevant knowledge about the target culture can definitely boost self-confidence since the communicators clearly know how to behave and how to express is more natural and appropriate, which will to some extent reduce uncertainty in the process of cross-cultural communication. Moreover, they will be motivated to engage in more such communication, so the negative feelings of anxiety, uncertainty, tension and even fear of failure will be gradually alleviated. If possible, people can be well-prepared before attending some intercultural activities. 
In addition, with the accumulation of relevant cultural knowledge, people's cultural sensitivity will also be promoted and they will no longer overlook the differences among cultures; instead, they will try to respect and even appreciate the new culture. In fact, some people's understanding of another group is only based on the ideas in the long past, or just from the partial understanding of some developed regions or remote areas of that culture; however, the world is always changing, understanding from some people is still not comprehensive. So, the consistent learning is inevitable for a good intercultural communicator.

\section{B. Cultivation of Empathy}

The consciousness of empathy in the process of cross-cultural interaction should be developed. Empathy refers to the ability to think from others' standpoints, which is an effective skill for cross-cultural communication. With empathy, they can consciously get rid of their own cultural shackles and try to respect, feel and understand the new cultural customs. After knowing the cultural differences, not to assume the new culture is totally strange even wrong for the first place, but to adopt a tolerant attitude of the new ways of doing things, is a necessary step for a better communication. To enhance the relationship with the people of the new cultural backgrounds, we are supposed to make efforts to put ourselves in the others' shoes.

Empathy could be practised by first becoming a good and patient listener, who can think from one's own and others' cultural points of view. Next, it is crucial to control criticism of the new culture and adopt a neutral attitude towards it. Trying to be empathetic is not to suggest that one has to accept the new culture, but he will have a better understanding of the new culture when viewing it from others' cultural perspective.

\section{Development of Independent Thinking}

The cultivation of the independent thinking matters a lot for a better understanding of a new culture, which means that people can think, analyze and judge something by themselves instead of coming to a conclusion based on hearsay. Forming the ability of independent thinking is particularly important in avoiding the tendency of stereotyping and prejudice. People can make a comprehensive judgment by finding out more information and taking part in more practical intercultural interactions. People also need to search the information from the multiple perspectives. In addition, independent thinking requires people to have a lot of patience. When people intuitively start to bias against others, they should first wait a little bit, spend some time for full analysis and finally make a judgment. Another way of developing the independent thinking is as the saying goes, circumstances alter cases. To judge the people with different cultural backgrounds, the intercultural communicators should try to analyze the specific problem based on the related situations instead of just relying on the previous perceptions.

\section{More Practice of Interaction}

With the aim of conducting a better intercultural communication, learning the relevant knowledge about the target culture is not enough, having more real interaction and enhancing practical exchange is very significant to overcome the affective barriers. Having more interaction practice enables people to open themselves to others and to have more opportunities to be closer to the new culture. In this active interaction process, people exchange their own cultural ideas, even some completely different ways, with the possible result of partial or full understanding with each other, which definitely helps to change the previous negative opinion towards certain group of people. At the same time, through active interaction, people can get more chances to have the face-to-face contact with others, more convenient for them to remove the negative stereotyping since people have the opportunity to recognize the individuality. Moreover, in this active process, it is possible to foster empathy mentioned above to at least alleviate the wrong perception in that people could find out more similarities and the positive sides which were the negative side thought before. When they learn more about each other, the racism may gradually decrease even fade away.

All in all, a good intercultural communicator should cultivate the flexible and broadminded manner to accommodate multiculturalism instead of ethnocentrism, even develop the intercultural personalities.

\section{CONCLUSION}

The world we are living in is becoming smaller and smaller since technology is rapidly shortening the distance between the people in different countries. People can communicate in the ways they could never dream of years before thanks to the widespread globalization. So our neighbors are becoming those who speak different languages and have different values and lifestyles. Besides, the goal of language learning is not only to learn the language itself, but also to understand and even effectively communicate with people from other cultures. However, it is not very easy, but if we attach great importance to intercultural barriers, like the affective barriers, and try to adopt feasible and effective strategies, it is possible to minimize and even remove some negative deep-rooted conceptions, to facilitate a better intercultural communication and to avoid the bad consequences the conflicts may lead to.

Since change is inevitable for everything, we should see things in the light of their development and get rid of the rigid old view. For a better future, opposition between cultures should be replaced by respect and cooperation with each other to gain the mutual benefits for two or more sides. 


\section{REFERENCES}

[1] Cao, Yue. (2019). Cultural Differences in International Business Negotiation. Master thesis, Shenyang Institute of Engineering.

[2] Gudykunst, B. William. (2007). Cross-cultural and Intercultural Communication. Shanghai: Shanghai Foreign Language Education Press.

[3] Li Xiaoxia. (2002). A Comparative Study on Chinese and American Verbal Communication Patterns. Master thesis, Zhengzhou University.

[4] Li Zhuofeng. (2010). Bridging the Gap: Intercultural Friendship between Chinese and Americans. Master thesis, Liberty University.

[5] Pang Huihui. (2010). A Comparative Study on the Perception of Friendship between American and Chinese University Students. Master thesis, Xi'an International Studies University.

[6] Starosta J. Willam, Chen Guoming. (2007). Foundations of Intercultural Communication. Shanghai: Shanghai Foreign Language Education Press.

[7] Wang Weibo, Che Lijuan. (2008). Intercultural Communication in Business. Beijing: Foreign Language Teaching and Research Press.

[8] Yan Ming. (2009). Intercultural Communication for College Students. Beijing: Tsinghua University Press.

[9] Yu Huiying. (2009). A Contrastive Study on Face-saving Devices in English and Chinese Verbal Communication. Master thesis, Jilin University.

Sha Zhu is currently a lecturer in the School of Foreign Languages, Huaiyin Institute of Technology, Huai'an, Jiangsu Province of China. Her research interests include intercultural communication and educational pedagogy. 